\title{
www.czasopisma.pan.pl \\ Mechanical Properties of Magnesium Alloys Produced by the Heated Mold Continuous Casting Process
}

\author{
M. Okayasu ${ }^{\text {a, }}$ *, S. Wu ${ }^{\text {a }}$, T. Tanimoto ${ }^{\text {a }}, \mathrm{S}$. Takeuchi ${ }^{\mathrm{b}}$ \\ ${ }^{a}$ Graduate School of Natural Science and Technology, Okayama University \\ 3-1-1 Tsushimanaka, Kita-ku, Okayama, 700-8530, Japan \\ ${ }^{\mathrm{b}}$ Graduate School of Science and Technology, Ehime University \\ 3 Bunkyo-cho, Matsuyama, Ehime, 790-8577, Japan \\ * Corresponding author. E-mail address: okayasu@okayama-u.ac.jp
}

Received 19.05.2016; accepted in revised form 28.07.2016

\begin{abstract}
Investigation of the tensile and fatigue properties of cast magnesium alloys, created by the heated mold continuous casting process (HMC), was conducted. The mechanical properties of the Mg-HMC alloys were overall higher than those for the $\mathrm{Mg}$ alloys, made by the conventional gravity casting process $(\mathrm{GC})$, and especially excellent mechanical properties were obtained for the $\mathrm{Mg}_{97} \mathrm{Y}_{2} \mathrm{Zn}_{1}-\mathrm{HMC}$ alloy. This was because of the fine-grained structure composed of the $\alpha$-Mg phases with the interdendritic LPSO phase. Such mechanical properties were similar levels to those for conventional cast aluminum alloy $\left(\mathrm{Al}_{84.7} \mathrm{Si}_{10.5} \mathrm{Cu}_{2.5} \mathrm{Fe}_{1.3} \mathrm{Zn}_{1}\right.$ alloys: $\mathrm{ADC1}$ ), made by the GC process. Moreover, the tensile properties $\left(\sigma_{\mathrm{UTS}}\right.$ and $\left.\varepsilon_{\mathrm{f}}\right)$ and fatigue properties of the $\mathrm{Mg}_{97} \mathrm{Y}_{2} \mathrm{Zn}_{1}-\mathrm{HMC}$ alloy were about 1.5 times higher than that for the commercial $\mathrm{Mg}_{90} \mathrm{Al}_{9} \mathrm{Zn}_{1}-\mathrm{GC}$ alloy (AZ91). The high correlation rate between tensile properties and fatigue strength (endurance limit: $\sigma_{1}$ ) was obtained. With newly proposed etching technique, the residual stress in the $\operatorname{Mg}_{97} \mathrm{Y}_{2} \mathrm{Zn}_{1}$ alloy could be revealed, and it appeared that the high internal stress was severely accumulated in and around the long-period stacking-order phases (LPSO). This was made during the solidification process due to the different shrinkage rate between $\alpha$-Mg and LPSO. In this etching technique, microcracks were observed on the sample surface, and amount of micro-cracks (density) could be a parameter to determine the severity of the internal stress, i.e., a large amount to micro-cracks is caused by the high internal stress.
\end{abstract}

Keywords: Magnesium alloy; Unidirectional solidification, Continuous casting; Mechanical property; Microstructural characteristic

\section{Introduction}

In recent years, magnesium alloys have received special attention due to their low density. Although $\mathrm{Mg}$ alloys are expected to make replacement with the other metals (steel and aluminum alloys), there would have several problems, e.g., poor mechanical properties (tensile strength and ductility). To date, a number of researchers have attempted to develop new Mg alloys, and one of the approaches is to employ ternary Mg-Y-Zn alloys. It is considered that the ternary magnesium alloys have superior strength and high ductility compared to commercial Mg alloys. Such excellent mechanical properties could be caused by unique microstructural formation, i.e., long-period stacking-order phase (LPSO) [[1]]. In the study by Yamasaki et al., [[2]] the high tensile properties of the extruded $\mathrm{Mg}-\mathrm{Y}-\mathrm{Zn}$ alloy have been developed $\left(\sigma_{\mathrm{UTS}}=380 \mathrm{MPa}\right.$ and $\varepsilon_{\mathrm{f}}=8 \%$ ), where the microstructural formations were controlled, e.g., a recrystallized fine $\alpha$-Mg phase, 
a worked coarse $\alpha$-Mg phase, and a fiber-shaped LPSO phase. There is unique interaction between the LPSO phase and the deformation twin in $\mathrm{Mg}-\mathrm{Zn}-\mathrm{Y}$ alloy, and the growth of deformation twin in the $\{10 \overline{1} 2\}$ is prevented by the densely populated LPSO phase, providing high strength and high ductility [[3]]. Datta et al. have made a first-principles study to assess stability of the periodic structures with different stacking sequences in $\mathrm{Mg}-\mathrm{Zn}-\mathrm{Y}$ alloys, and it appears that $\mathrm{Y}$ stabilizes the long periodicity, whereas the mechanical properties are improved severely by $\mathrm{Zn}$ doping [[4]]. Hagihara et al. [[5]] have reported that basal slip in $\mathrm{Mg}_{12} \mathrm{YZn}$ with 18R long-period stacking is dominant operative deformation mode, and this critical resolved shear stress is found to be $10-30 \mathrm{MPa}$. Moreover, the stress applied to parallel to the basal plane makes deformation kinks, and their results lead to that the plastic behavior of the LPSO Mg$\mathrm{Zn}-\mathrm{Y}$ base alloys is highly anisotropic [[5]]. On the basis of the above reports, it is considered that the control of the microstructure is significantly important to improve the mechanical properties of the Mg alloys.

To improve the material properties of the magnesium alloys, severe deformation has been applied to the associated magnesium alloys. In this instance, equal channel angular extrusion is conducted in Mg-Ni-Y-Re alloy to create fine-grained microstructure, and the ultimate tensile strength enhances significantly about $391 \mathrm{MPa}$, because of the grain refinement of less than $1 \mu \mathrm{m}$ by one pass at 583K [[6]]. Xu et al. [[7]] have examined microstructure and mechanical properties of the rolled sheets of Mg-Gd-Y-Zn-Zr alloy. The sheet, which rolled from the as-cast $\mathrm{Mg}$ alloy, has been composed of recrystallized $\alpha-\mathrm{Mg}$ grains surrounded by $\mathrm{Mg}_{3}(\mathrm{Gd}, \mathrm{Y})$ eutectic compounds; while the rolled sheet from as-homogenized alloy is composed of largely deformed grains with LPSO phase inside and fewer recrystallized $\alpha-\mathrm{Mg}$ grain. This microstructural formation has exhibited higher mechanical properties, e.g., $\sigma_{\mathrm{UTS}}=373 \mathrm{MPa}[[7]]$.

In our previous studies, the heated mold continuous casting process (HMC) has been used to make the high-strength $\mathrm{Al}$ alloys [[8]]. With the HMC process, melt alloys are unidirectionally solidified at a high cooling rate. Because the HMC samples are formed with fine grains, uniformly organized crystal orientation and less cast defects, the excellent mechanical properties can be obtained, namely high strength and high ductility [[8]]. The concept of HMC process was originally proposed by Ohno [[9]] several decades ago. Following the invention, the HMC process has been exploited by many scientists around the world. However, in our belief, there is no clear approach to create the cast LPSO$\mathrm{Mg}$ alloys by the HMC process. This is because, in the HMC process, the liquid $\mathrm{Mg}$ alloy has to be solidified by the direct water cooling, which makes dangerous situation. Thus, the aim of this study is first to make the LPSO-Mg alloys by HMC, where our originally proposed HMC system was used. Furthermore, the mechanical properties of the HMC-Mg alloys are examined systematically.

\section{Experimental procedures}

\subsection{Material preparation}

In the present work, a cast magnesium alloy, $\mathrm{Mg}_{97} \mathrm{Y}_{2} \mathrm{Zn}_{1}$, was employed to examine the mechanical properties. Two different cast $\mathrm{Mg}$ alloy samples were prepared, one by the gravity casting (YZ-GC) and the heated mold continuous casting process (YZHMC). The YZ-GC samples, with dimensions $\phi 10 \times 100 \mathrm{~mm}$, were manufactured in the argon atmosphere. For the HMC sample, the round rod sample with $\phi 5 \mathrm{~mm} \times 1 \mathrm{~m}$ in length was produced. Note that the size of the cast sample for $\mathrm{HMC}$ and $\mathrm{GC}$ is designed with different size (diameter) due to the technical difficulty for creating the thin cast rod by the GC process, i.e., high viscosity of the $\mathrm{Mg}$ alloy. However, we believe that the experimental approaches to obtain their mechanical properties would be acceptable, since no clear cast defects were detected in all test specimens. Figure 1 shows a schematic diagram of the horizontal-type heated continuous casting arrangement designed originally.

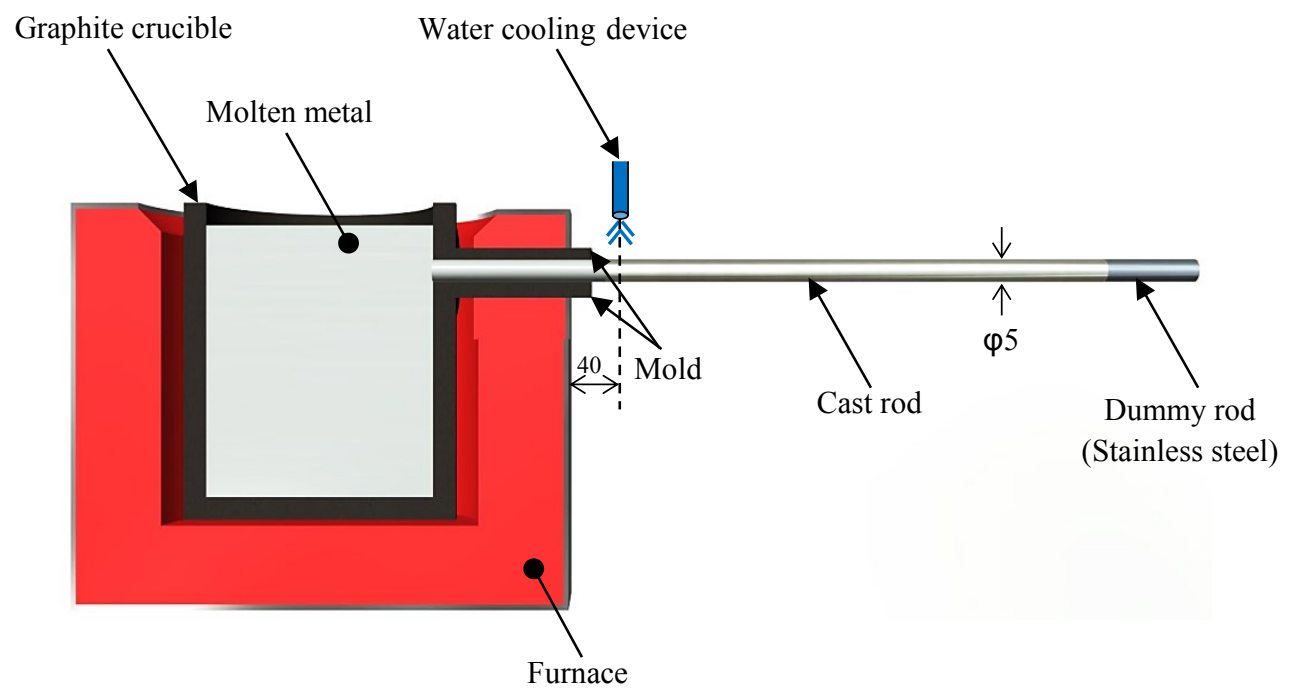

Fig. 1. Schematic illustration of the heated mold continuous casting device. 
The HMC device consists of a melting furnace, a graphite mold, a graphite crucible, a cooling device and pinch rolls for withdrawal of the cast rod sample. A graphite mold, heated to $918 \mathrm{~K}$, was connected to the graphite crucible directly, where the head of the mold was machined with $5 \mathrm{~mm}$ in diameter. $\mathrm{Mg}_{97} \mathrm{Y}_{2} \mathrm{Zn}_{1}$ alloy (about $0.2 \mathrm{~kg}$ ) was placed in the graphite crucible for melting at $918 \mathrm{~K}$. During the casting process, the system was completely shielded by high-purity argon gas to prevent oxidization and ignition. The melt $\mathrm{Mg}$ alloy was fed by the dummy rod into the graphite mold at $1.9 \mathrm{~mm} / \mathrm{s}$ continuously. The cast sample was solidified directly by water droplets (at about $80 \mathrm{ml} / \mathrm{min}$ ).

\subsection{Mechanical testing}

Mechanical properties were investigated at room temperature using an electro-servo-hydraulic system with $50 \mathrm{kN}$ capacity. In this approach, tensile and fatigue properties were examined experimentally, where dumbbell shape test specimens were used with dimensions $\phi 4 \mathrm{~mm}$ with $10 \mathrm{~mm}$ gauge length. The tensile properties (ultimate tensile strength $\sigma_{\mathrm{UTS}}$ and strain to failure $\varepsilon_{\mathrm{f}}$ ) were evaluated via engineering tensile stress - engineering tensile strain curves, which were monitored by a data acquisition system in conjunction with a computer through a standard load cell and strain gauge. The loading speed for the tensile test was determined to be $1 \mathrm{~mm} / \mathrm{min}$. On the other hand, the fatigue strength was examined from the relationship between the stress amplitude and cycle number to final failure, i.e. the $S-N$ curve. The tensile - tensile cyclic loading was applied continuously with a sinusoidal waveform at a frequency $30 \mathrm{~Hz}$ and at the load ratio $R=0.1$ up to $10^{7}$ cycles $\left(\sigma_{1}\right)$. The maximum stress $\left(\sigma_{\max }\right)$ values for this fatigue test were determined on the basis of the ultimate tensile strength.

Microstructural characteristics of both $\mathrm{Mg}_{97} \mathrm{Y}_{2} \mathrm{Zn}_{1}$ alloys were investigated using an optical microscope, a scanning electron microscope (SEM) and an energy dispersive x-ray spectroscope (EDX). Moreover, the crystal orientation and lattice strain were examined by an electron back scattering diffraction system (EBSD).

\subsection{Residual stress observation}

In the present study, an attempt was made to examine the extent and location of the internal stress in the cast $\mathrm{Mg}_{97} \mathrm{Y}_{2} \mathrm{Zn}_{1}$ alloy by a newly proposed etching technique. The etching process is briefly summarized as follows: (i) the sample surface for observation is polished to a mirror status using cloth with alumina particles; (ii) the polished surfaces are etched for $2 \mathrm{~min}$ with the following solution, e.g., $10 \mathrm{ml}$ nitric acid and $90 \mathrm{ml}$ methanol; and (iii) the sample surface is immersed in acetone for 48 hours before observation by scanning electron microscope.

\section{Results and discussion}

\subsection{Microstructural characteristics}

Figure 2 shows optical micrographs of the $\mathrm{Mg}_{97} \mathrm{Y}_{2} \mathrm{Zn}_{1}$ alloy (YZ) produced by the gravity casting and the heated mold continuous casting. The $\mathrm{Mg}$ alloy has a two-phase structure: the $\alpha$-Mg (bright region) and LPSO phases (dark region). For the YZHMC sample, the grain refinement of $\alpha-\mathrm{Mg}$ and LPSO occurs due to the rapid cooling process for HMC. Many LPSO phases are formed by the stripped shape, which are associated with the $\langle 0001\rangle$ phase of the hep structure as indicated on the photographs. The mean hardness of the $\alpha-\mathrm{Mg}$ and LPSO phases, examined by a micro-Vickers hardness tester, is $0.93 \mathrm{GPa}$ and $1.17 \mathrm{GPa}$ (standard deviation $(\mathrm{SD})<0.1$ ), respectively. The grain size for the HMC sample is apparently smaller than that for the GC one. Secondary dendrite arm spacing (SDAS) of both samples is 14.6 $\mu \mathrm{m}(\mathrm{SD}=1.33)$ for $\mathrm{YZ}-\mathrm{HMC}$ and $28.2 \mu \mathrm{m}(\mathrm{SD}=10.7)$ for $\mathrm{YZ}$ GC. In this case, SDAS was determined by the mean value of more than a hundred measurements. The differences in microstructural characteristics are affected by the different cooling speed during the casting process.

Fig. 2 displays the inverse-pole figure (IPF) maps showing the crystal orientation of both $\mathrm{Mg}$ alloys examined by EBSD, where the color levels of each pixel in the IPF maps are determined by the deviation of the measured orientation. As seen, there are several colonies in both samples, which consist of several grains and eutectic phases, combined together. The size of colony for the HMC sample seems to be smaller than that for the GC one. This may be related to their grain size. In our previous works, uniformly organized crystal orientations with fine grains were obtained in the HMC aluminum alloys [[10]], i.e. single crystallike formation, which made a high strength and high ductility. Dislike the Al-HMC alloys, crystal orientation was randomly obtained for the Mg-HMC alloys. The reason behind this is not clear at the moment, but this may be caused by the complicated lattice formation (hexagonal close-packed: hcp), compared to the cubic fcc.

\subsection{Mechanical properties}

Figure 3(a) shows representative stress-strain curves for various cast samples [[8],[11]], including both YZ-GC and -HMC samples. In this case, the related experimental data for several conventional $\mathrm{Al}$ and $\mathrm{Mg}$ alloys were plotted to verify the mechanical properties of the YZ alloys: AM60 $\left(\mathrm{Mg}_{93.9} \mathrm{Al}_{6} \mathrm{Mn}_{0.1}\right)$, AZ91 $\left(\mathrm{Mg}_{88.9} \mathrm{Al}_{9} \mathrm{Zn}_{2} \mathrm{Mn}_{0.1}\right)$ and $\mathrm{ADC} 12\left(\mathrm{Al}_{84.7} \mathrm{Si}_{10.5} \mathrm{Cu}_{2.5} \mathrm{Fe}_{1.3} \mathrm{Zn}_{1}\right)$. It is obvious that the tensile properties are different, and the tensile fracture stress $\left(\sigma_{\mathrm{UTS}}\right)$ and strain to failure $\left(\varepsilon_{\mathrm{f}}\right)$ obtained from the stress-strain relations are summarized in Fig. 3(b). The ultimate tensile strengths of the YZ-GC and YZ-HMC samples are $\sigma_{\mathrm{UTS}}=203 \mathrm{MPa}$ and $228 \mathrm{MPa}$, respectively. The tensile properties of the YZ-HMC samples are indicated relatively in the higher level compared to that for the other $\mathrm{Mg}$ alloys although the $\sigma_{\text {UTS }}$ value (for YZ-HMC) is slightly lower than that for AZ91- 
$\mathrm{HMC}$ and much lower than that for Al-HMC alloy (Al-Si-Cu based alloy: ADC12) [[12]].

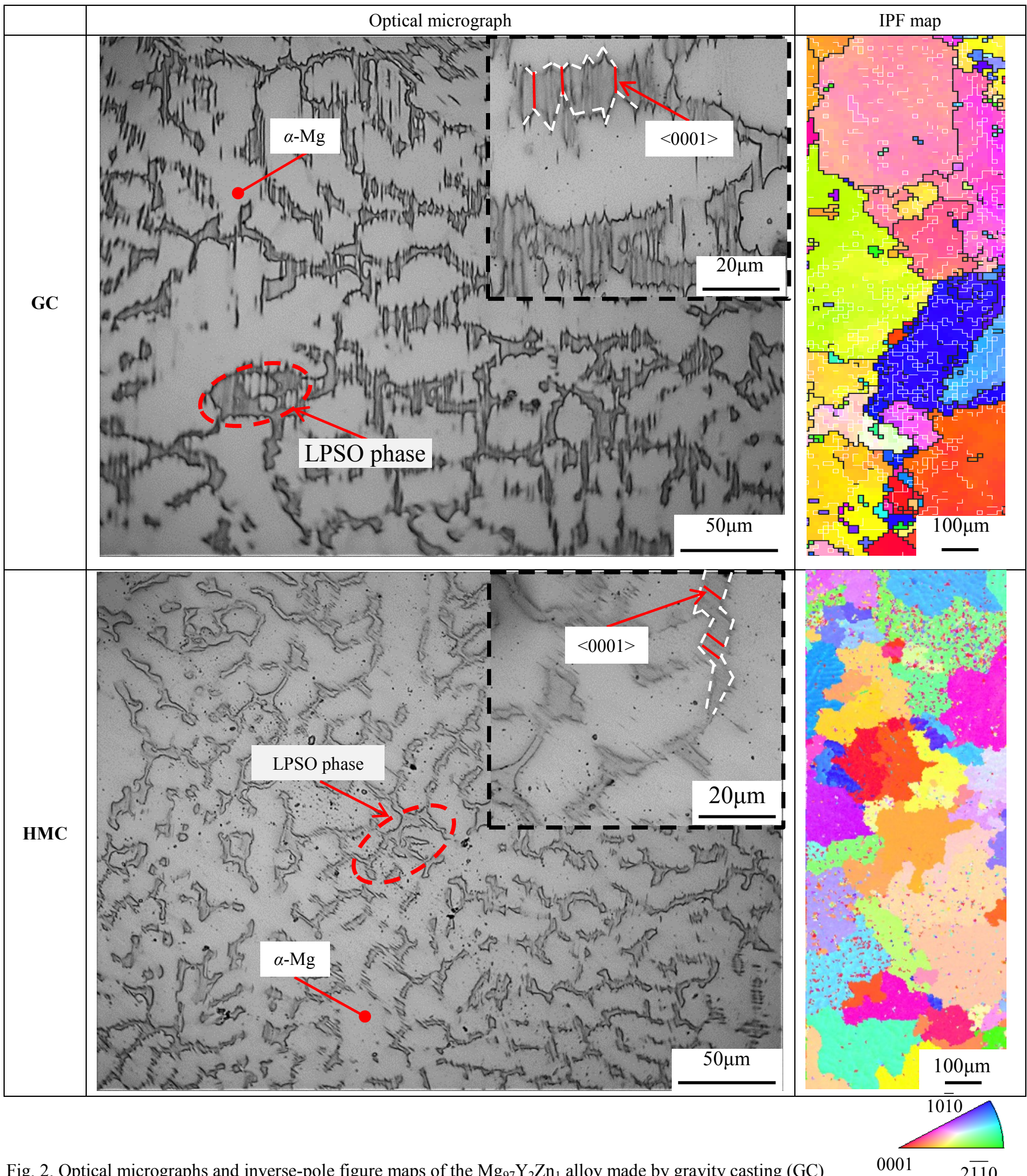

Fig. 2. Optical micrographs and inverse-pole figure maps of the $\mathrm{Mg}_{97} \mathrm{Y}_{2} \mathrm{Zn}_{1}$ alloy made by gravity casting (GC) and heated mold continuous casting (HMC) 
(a) Stress-strain curves

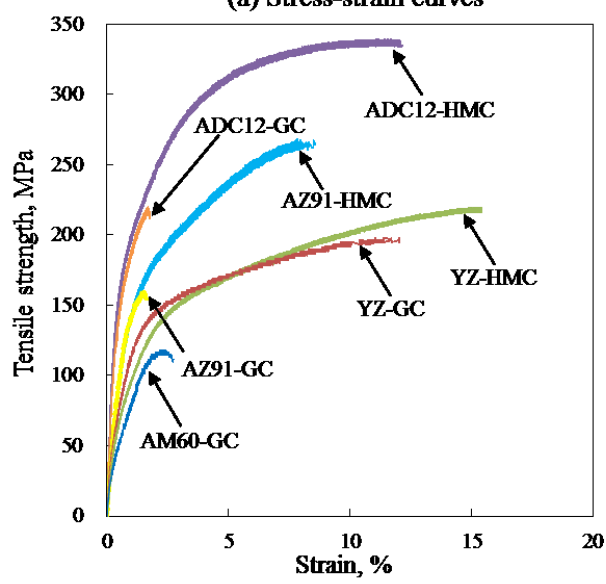

(b) Ultimate tensile strength $\left(\sigma_{\text {UTS }}\right)$

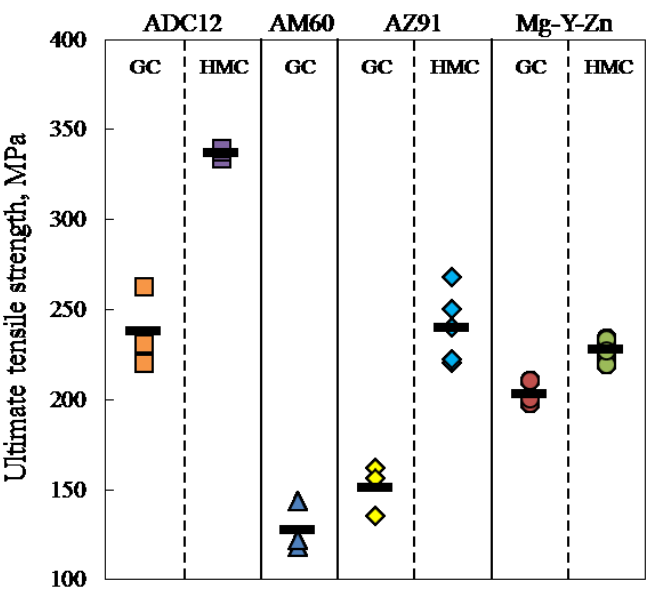

(c) Fracture strain $\left(\varepsilon_{\mathrm{f}}\right)$

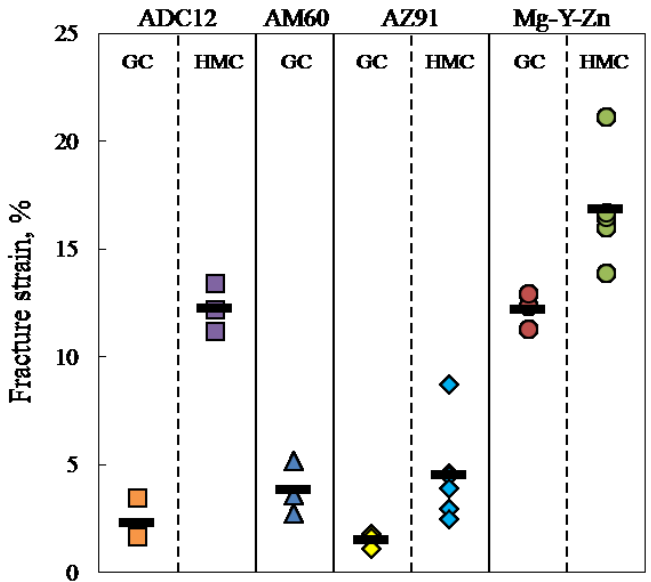

Fig. 3. Tensile properties of various cast samples, including YZGC and -HMC samples: (a) stress-strain curves, (b) ultimate tensile strength $\left(\sigma_{\mathrm{UTS}}\right)$ and $(\mathrm{c})$ fracture strain $\left(\varepsilon_{\mathrm{f}}\right)$
On the other hand, the fracture strains of YZ-HMC $\left(\varepsilon_{\mathrm{f}}=17 \%\right)$ is approximately four times as high as that for the AZ91-HMC samples. In addition, the $\varepsilon_{\mathrm{f}}$ value for YZ-HMC is higher than that for the ADC12-HMC samples. This may be attributed to the high quality cast $\mathrm{Mg}$ alloy with fine microstructures and severe kink and slip deformation [[13]]. Figure 4 shows the inverse-pole figure (IPF) map and misorientation (MO) map for the YZ-GC sample around the fracture surface after the tensile test. Note that the misorientation angles indicated by the blue color are less than $5^{\circ}$. From the IPF map, the crystal orientations show complicated structure. As indicated by the arrows, the direction of $c$-axis for hcp structure was altered due to the severe strain. Such severe strain can be verified from the MO maps, where a high density of the high misorientation angle (more than $5^{\circ}$ ) is distributed in and around the colonies.

Figure 5 shows the relationship between stress amplitude and fatigue life (the $S$ - $N$ curve) for various materials including YZ-GC and -HMC samples. Note that the arrows indicated in this figure are the specimens which did not fracture within $10^{6}$ or $10^{7}$ cycles, namely endurance limit $\left(\sigma_{1}\right)$. As seen, the fatigue strength of the YZ-HMC samples is higher than that for the other Mg alloys; the mean endurance limits at $10^{7}$ cycles for the YZ-HMC are about $51 \mathrm{MPa}$, which is about 1.5 times higher than that for YZ-GC and AZ91-HMC, and about twice high compared to that for AM60GC [[14]]. However, the $S-N$ curve of the YZ-HMC sample is located in the lower level compared to that for the aluminum alloys (ADC12-GC and -HMC) [[8]].

A comparison of YZ-HMC and AZ91-HMC shows the higher $\sigma_{\mathrm{l}}$ and the higher $\varepsilon_{\mathrm{f}}$ for YZ-HMC, while the lower $\sigma_{\mathrm{UTS}}$ for YZHMC. The relationship between the $\sigma_{1}$ and tensile properties were investigated. Figure 6 shows plots of the endurance limit versus the tensile properties $\left(\sigma_{\mathrm{UTS}}\right.$ and $\left.\varepsilon_{\mathrm{f}}\right)$ for various associated $\mathrm{Mg}$ alloys, including the YZ-GC and -HMC samples. Note first that the endurance limits were defined at $10^{7}$ cycles, and the data plots were used only for the magnesium alloys. As in Fig. 6, there are linear relationships between $\sigma_{1}$ and tensile properties at high correlation rates of more than 0.6 .

To further understand the fatigue strength of the associated $\mathrm{Mg}$ alloys, the fatigue strength coefficient $\left(\sigma_{\mathrm{f}}\right)$ was examined, where the $S-N$ curves are estimated by a power law dependence of the applied cyclic stress and cycle number to final fracture [[15]]:

$$
\sigma_{\mathrm{a}}=\sigma_{\mathrm{f}} N_{\mathrm{f}}^{\mathrm{b}}, \mathrm{MPa}
$$

where $N_{\mathrm{f}}$ is the cycle number to final fracture.

In this case, the $\sigma_{\mathrm{f}}$ value is related to the slope of $S-N$ curve. The $\sigma_{\mathrm{f}}$ values, obtained by least squares analysis, are then plotted with their tensile properties in Figure 7: (a) $\sigma_{\mathrm{f}}$ vs. $\sigma_{\mathrm{UTS}}$ and (b) $\sigma_{\mathrm{f}}$ vs. $\varepsilon_{\mathrm{f}}$. As seen, data plots are scattered widely, and no clear correlation between $\sigma_{\mathrm{f}}$ and tensile properties are obtained: $R^{2}$ value is less than 0.1. Such weak correlation may be interpreted by the following reason: the fatigue strength coefficient (the slope of the $S-N$ curve) can be influenced by the tensile strength and the ductility. As the Mg alloys selected in this approach have various tensile properties: (i) YZ-HMC: high $\sigma_{\mathrm{UTS}}$ and high $\varepsilon_{\mathrm{f}}$, (ii) AZ91HMC: high $\sigma_{\mathrm{UTS}}$ and low $\varepsilon_{\mathrm{f}}$ and (iii) AM60-GC: low $\sigma_{\mathrm{UTS}}$ and low $\varepsilon_{\mathrm{f}}$, the weak correlation could be obtained. Such difference in the tensile properties may be caused by the different 
microstructural formations, e.g., Mg alloy with and without LPSO

phase.

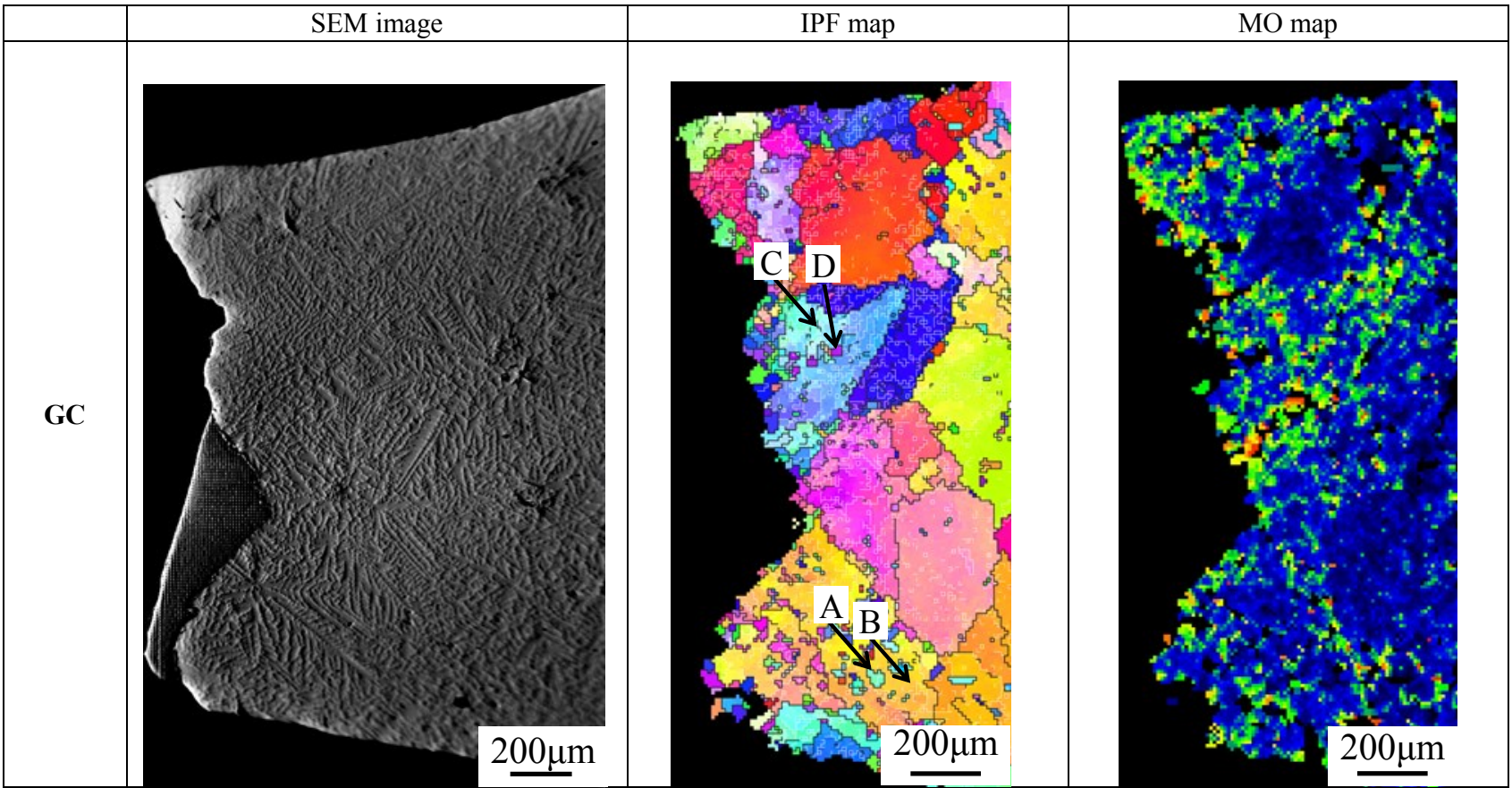

\begin{tabular}{|c|c|c|c|c|}
\hline $\mathrm{A}$ & $\mathrm{D}$ & D & Low MO: less than 5 ${ }^{\circ}$ \\
\hline
\end{tabular}

Fig. 4. Inverse-pole figure (IPF) map and misorientation (MO) map for YZ-GC sample around fracture surface after tensile test

\subsection{Residual stress observation}

Because of the complicated microstructural characteristics for the cast $\mathrm{Mg}_{97} \mathrm{Y}_{2} \mathrm{Zn}_{1}$ alloys, the residual stress could be accumulated during the solidification process. To examine this, an attempt was made to investigate the internal stress by the etching technique. Figure 8(a) displays the SEM images of the YZ-HMC sample, and Fig. 8(b) illustrates the model for the revelation of the internal stress. It is clear that a large number of micro-cracks are generated on the sample surface, and those cracks seem to be located in and around LPSO phases. In addition, several cracks generate along the $\langle 0001\rangle$ phase of the LPSO structure. Such high density of micro-crack could be related to the high internal stress, which created during the solidification process, due to the different shrinkage rate between the Mg matrix and LPSO phase. The essence of this etching technique for revelation of the residual stress can be explained as follows. The sample face becomes brittle by the oxidation via chemical reaction, and brittle oxide surface could be cracked due to the release of the high residual stress as shown in Fig. 8(b). In fact, with the EDX analysis on the etched surface, high amount of oxide (about 30\%) was detected. 


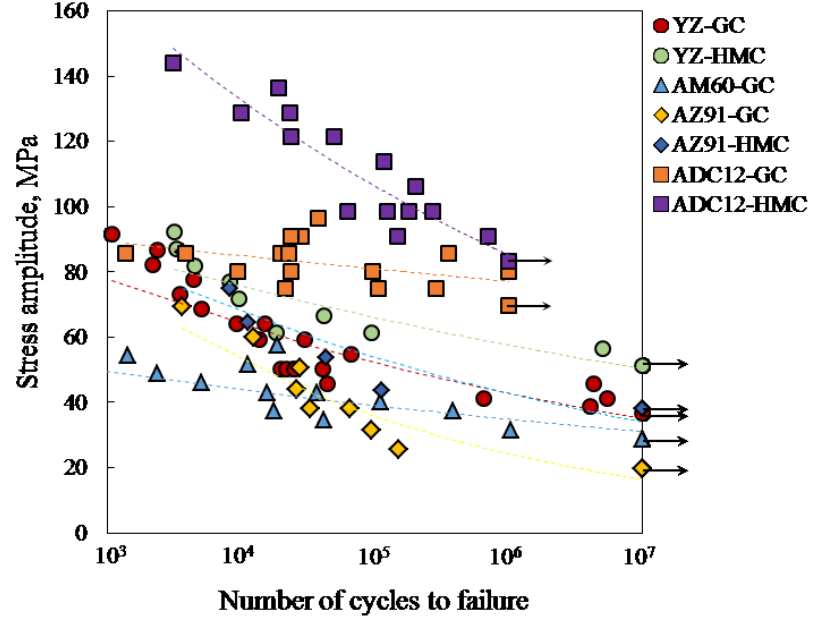

Fig. 5. $S-N$ curves for various cast samples, including YZ-GC and -HMC samples

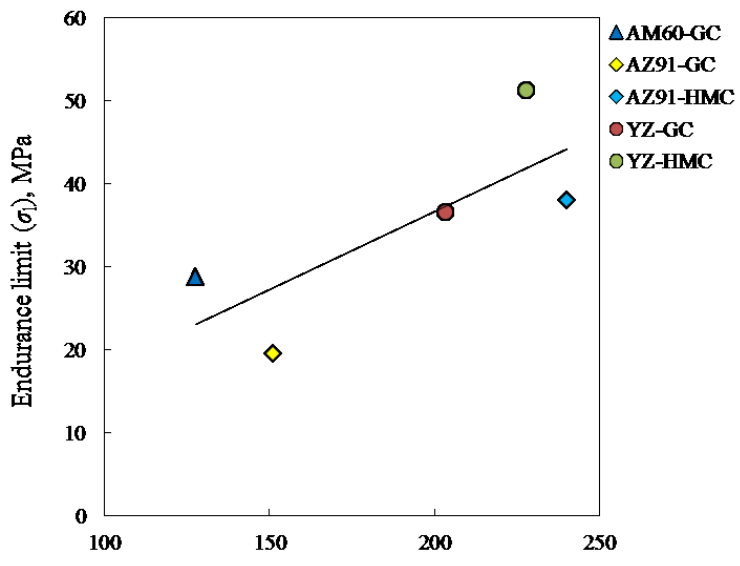

a)

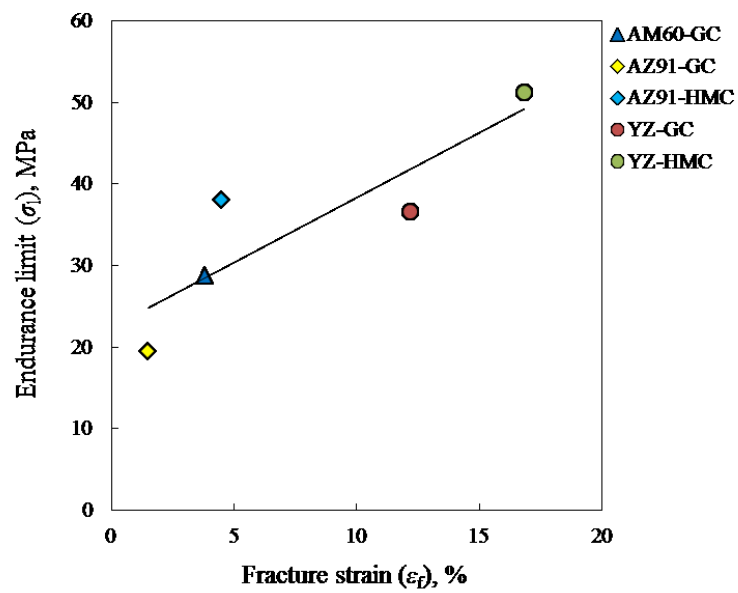

b)

Fig. 6. Relationship between the endurance limit and tensile properties: (a) $\sigma_{1}$ vs. $\sigma_{\mathrm{UTS}}$ and (b) $\sigma_{1}$ vs. $\varepsilon_{\mathrm{f}}$ a)

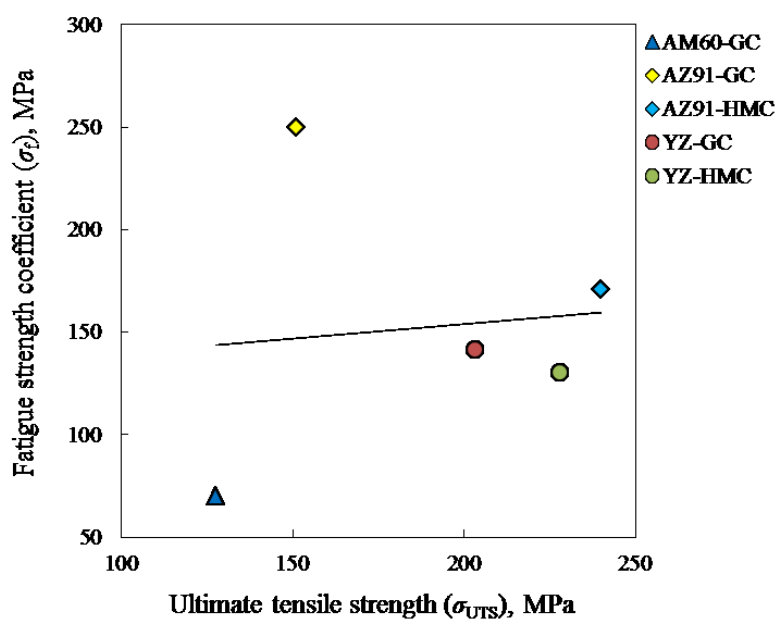

b)

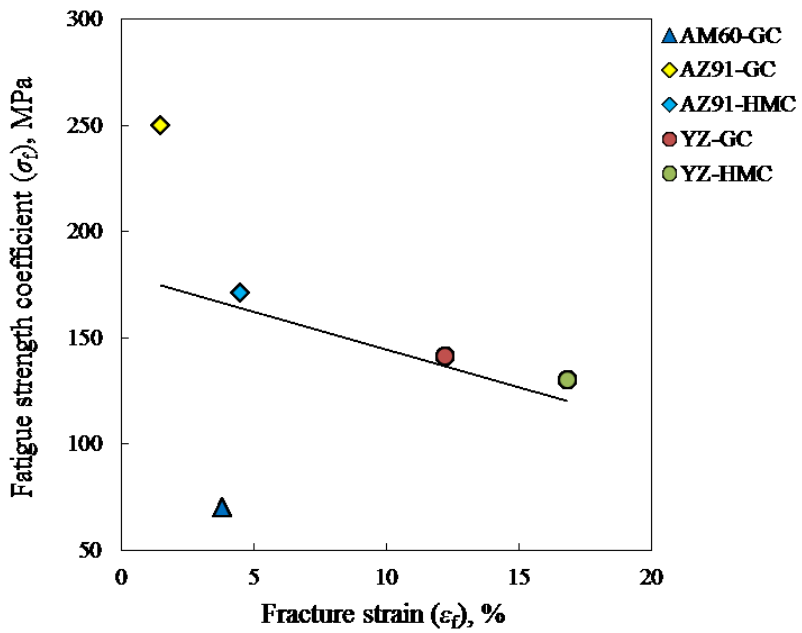

Fig. 7. Relationship between the fatigue strength coefficient and tensile properties: (a) $\sigma_{\mathrm{f}}$ vs. $\sigma_{\mathrm{UTS}}$ and (b) $\sigma_{\mathrm{f}}$ Vs. $\varepsilon_{\mathrm{f}}$ 
(a)
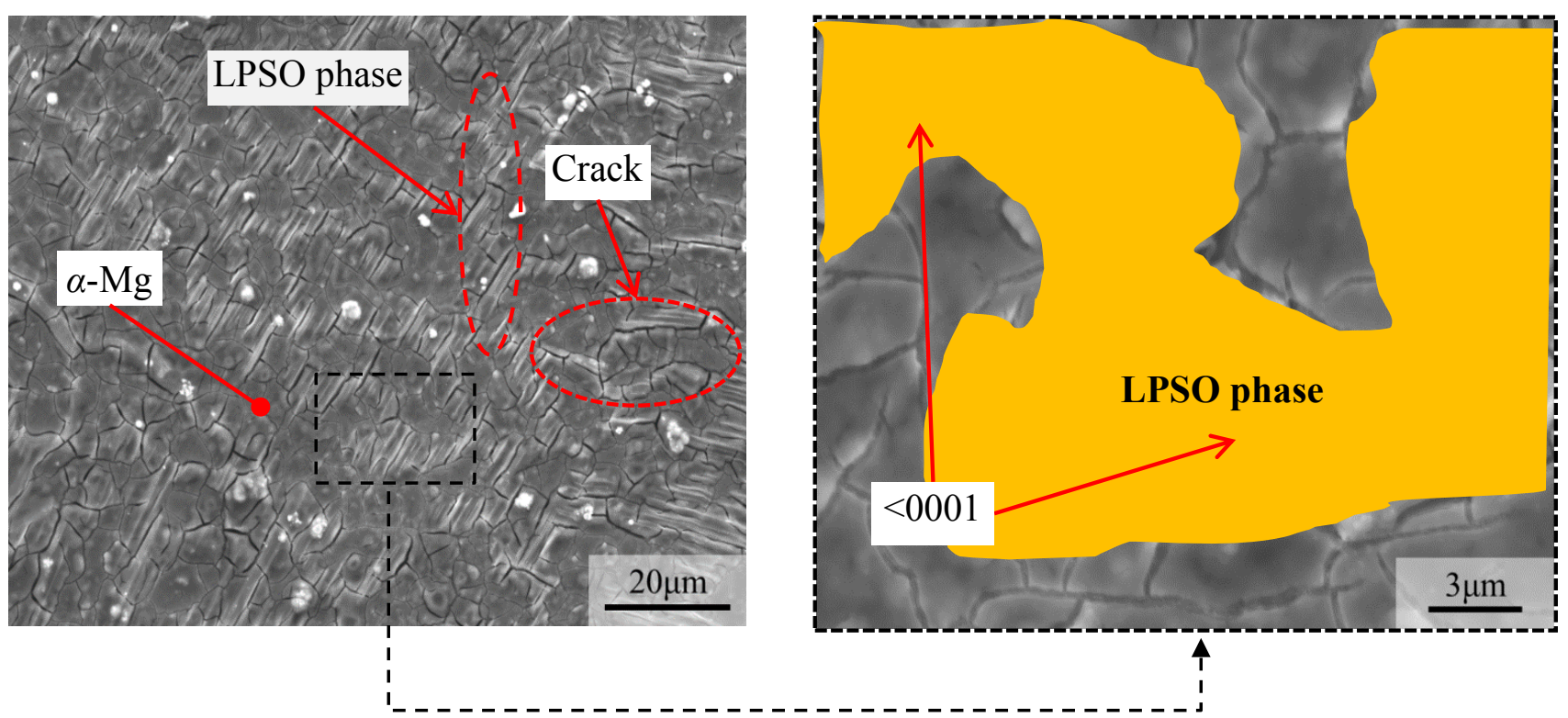

(b)

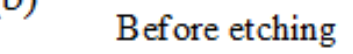

After etching and after acetone
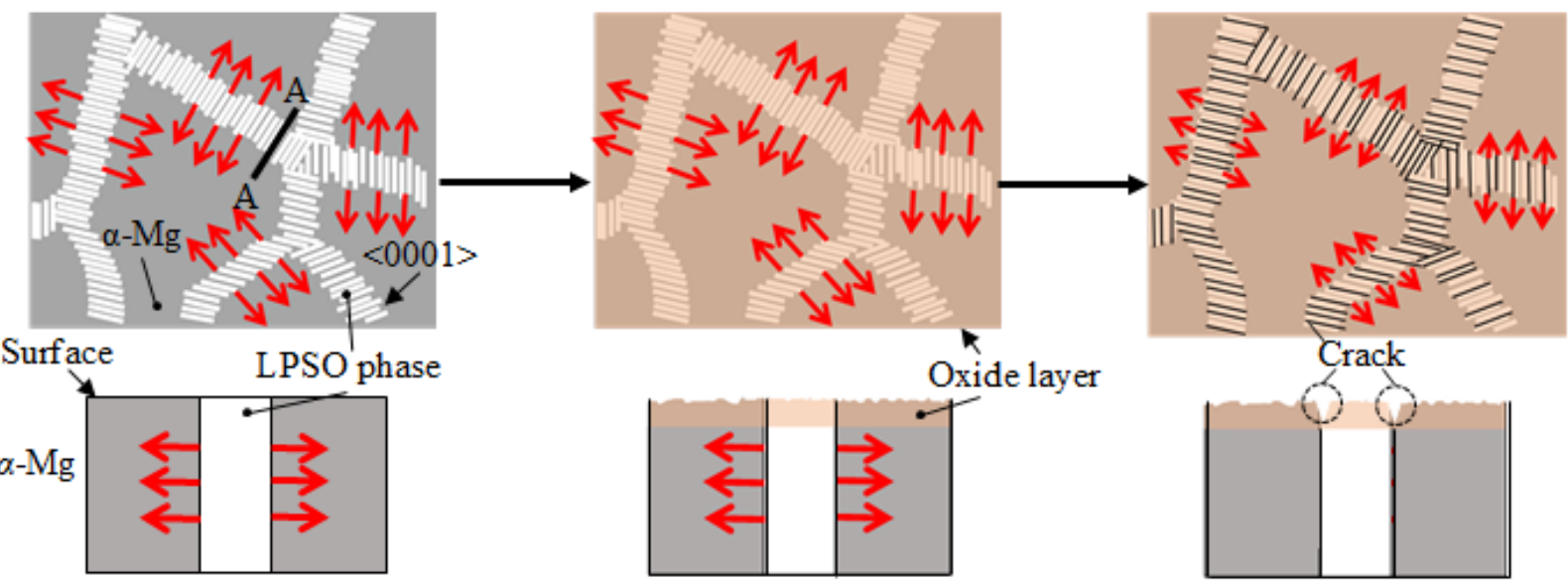

Fig. 8(a) SEM images of the YZ-HMC sample after the etching process, showing the residual stress areas indicated by different density of micro-cracks; Fig. 8(b) Schematic diagram showing the model of the revelation for the internal stress. 


\section{Conclusions}

The mechanical properties of $\mathrm{Mg}$ alloys produced by the heated mold continuous casting process were investigated. The results obtained are as follows:

1) The tensile properties $\left(\sigma_{\mathrm{UTS}}\right.$ and $\left.\varepsilon_{\mathrm{f}}\right)$ and fatigue strength for the YZ-HMC alloys are higher than those for the Mg-GC ones. This is because of the fine microstructure and LPSO phases. Such mechanical properties are similar levels to those for the ADC12-GC alloys. The endurance limits for the cast $\mathrm{Mg}$ alloys are correlated well with their $\sigma_{\mathrm{UTS}}$ and $\varepsilon_{\mathrm{f}}$, although the fatigue strength coefficient is not related to their tensile properties.

2) Randomly distributed crystal orientation is obtained for $Y Z$ $\mathrm{HMC}$ alloys even if the unidirectional solidification process is carried out. Unlike the Mg-HMC alloys, a uniformly obtained crystal orientation is successfully made for ADC12-HMC alloys. Such a random crystal orientation would be caused by the complicated lattice formation of hep structure, compared to the fcc one.

3) With our new etching technique, residual stress in the YZHMC alloy can be revealed, in which the high internal stress is observed in and around the LPSO structures. Such internal stress could be created in the solidification process, since there are different shrinkage rate between $\mathrm{Mg}$ matrix and LPSO phase.

\section{Acknowledgements}

The authors would like to acknowledge the sample preparation and financial support by Ochi foundry Inc. The authors also appreciate the technical supports and helpful comments by Professor M. Yamasaki.

\section{References}

[1] Lapovok, R., Gao, X., Nie, J-F., Estrin, Y. \& Mathaudhu, S.N. (2014). Enhancement of properties in cast $\mathrm{Mg}-\mathrm{Y}-\mathrm{Zn}$ rod processed by severe plastic deformation. Mater. Sci. Eng. A 615, 198-207.

[2] Yamasaki, M., Hashimoto, K., Hagihara, K. \& Kawamura, Y. (2011). Effect of multimodal microstructure evolution on mechanical properties of $\mathrm{Mg}-\mathrm{Zn}-\mathrm{Y}$ extruded alloy. Acta Mater. 59, 3646-3658.
[3] Matsuda, M., Ando, S. \& Nishida, M. (2005). Dislocation structure in rapidly solidified $\mathrm{Mg}_{97} \mathrm{Zn}_{1} \mathrm{Y}_{2}$ alloy with long period stacking order phase. Mater. Trans. 46, 361-363.

[4] Datta, A., Waghmare, U.V. \& Ramamurty, U. (2008). Structure and stacking faults in layered $\mathrm{Mg}-\mathrm{Zn}-\mathrm{Y}$ alloys: a first-principles study. Acta Mater. 56, 2531-2539.

[5] Hagihara, K., Yokotani, N. \& Umakoshi, Y. (2010). Plastic deformation behavior of $\mathrm{Mg}_{12} \mathrm{YZn}$ with 18R long-period stacking ordered structure. Intermetallics. 18, 267-276.

[6] Eddahbi, M., Pérez, P., Monge, M.A., Garcés, G., Pareja, R. \& Adeva, P. (2009). Microstructural characterization of an extrude $\mathrm{Mg}-\mathrm{Ni}-\mathrm{Y}-\mathrm{Re}$ alloy processed by equal channel angular extrusion. J. Alloys Compd. 473, 79-86.

[7] $\mathrm{Xu}, \mathrm{C}$. , Zheng, M.Y., Xu, S.W., Wu, K., Wang, E.D., Kamado, S., Wang, G.J. \& Lv, X.Y. (2012). Microsstructure and mechanical properties of rolled sheets of $\mathrm{Mg}-\mathrm{Gd}-\mathrm{Y}-\mathrm{Zn}-$ $\mathrm{Zr}$ alloy: as-cast versus as-homogenized. J. Alloys Compd. $528,40-44$

[8] Okayasu, M., Ota, K., Takeuchi, S., Ohfuji, H. \& Shiraishi, T. (2014). Influence of microstructural characteristics on mechanical properties of ADC12 aluminum alloy. Mater. Sci. Eng. A 592, 189- 200.

[9] Ohno, A. (1987). Solidification, $1^{\text {st }}$ ed. Springer. Germany., pp.113-118.

[10] Okayasu, M.\& Yoshie, S. (2010). Mechanical properties of $\mathrm{Al}-\mathrm{Si}_{13}-\mathrm{Ni}_{1.4}-\mathrm{Mg}_{1.4}-\mathrm{Cu}_{1}$ alloys produced by the Ohno continuous casting process. Mater. Sci. Eng. A 527, 31203126.

[11] Okayasu, M. \& Takeuchi, S. (2014). Mechanical properties and Failure Characteristics of $\mathrm{Mg}-9 \% \mathrm{Al}-1 \% \mathrm{Zn}$ alloys: Tensile Properties. Metall. Mat. Trans. A 45, 5767-5776.

[12] Okayasu, M., Takeuchi, S. \& Ohfuji, H. (2014). Mechanical strength and failure characteristics of cast Mg-9 pct Al-1 pct $\mathrm{Zn}$ alloys produced by a heated-mold continuous casting process: tensile properties. Metall. Mat. Trans. A 45, 57675776.

[13] Okayasu, M., Takeuchi, S., Matsushita, M., Tada, N., Yamasaki, M. \& Kawamura, Y. (2016). Mechanical properties and failure characteristics of cast and extruded $\mathrm{Mg}_{97} \mathrm{Y}_{2} \mathrm{Zn}_{1}$ alloys with LPSO phase. Mater. Sci. Eng. A 652, 14-29.

[14] Okayasu, M. \& Takeuchi, S. (2014). Mechanical strength and failure characteristics of cast $\mathrm{Mg}-9 \% \mathrm{Al}-1 \% \mathrm{Zn}$ alloys produced by a heated-mold continuous casting process: Fatigue properties. Mater. Sci. Eng. A 600, 211-220.

[15] Puchi-Cabrera, E.S., Staia, M.H., Quinto, D.T., VillalobosGutiérres, C.\& Ochoa-Pérez, E. (2007). Fatigue properties of a SAE4340 steel coated with TiCN by PAPVD. Int. J. Fatigue. 29, 471-480. 